\title{
Impact of the Integrated Management System on the Employees' Satisfaction Rate in the Technical Institutes
}

\author{
Salman S. Al-Githami ${ }^{1}$, Abdel Hamid M.S. Esmail ${ }^{2 *}$
}

${ }^{1}$ Development \& Quality Assurance / Computer and Information Technology skills Department, Jubail Technical Institute, Education Sector, Royal Commission for Jubail \& Yanbu, KSA

${ }^{2}$ Development \& Quality Assurance / Chemical skills Department, Jubail Technical Institute, Education Sector, Royal Commission for Jubail \& Yanbu, KSA

\author{
DOI: $10.36348 /$ jaep.2020.v04i02.005 \\ | Received: 06.02.2020 | Accepted: 22.02.2020 | Published: 29.02.2020 \\ *Corresponding author: Abdel Hamid M.S. Esmail
}

\section{Abstract}

The Integrated Management System (IMS) could consider as one of the most important factors that eases the process of integrating many quality and safety management systems into one system to facilitate the implementation of the systems requirements. Jubail Technical Institute (JTI) obtained ISO 9001 certificate in 2015, followed by several certificates such as ISO 22000, OHSAS 18001 and ISO 10015 respectively. These certificates and others made it necessary for JTI to unify efforts and increase the effectiveness of meeting the requirements of these systems. The used tool for achieving these purposes was the MISWEB which is an internal website that organizes the integration of quality and safety management systems in IMS and provides many internal services. Throughout the MISWEB, JTI has been developed many electronic procedures, documents and forms to communicate them for the sake of increasing the use of forms, procedures. In this case study, the impact of IMS (ISO 9001, ISO 22000, OHSAS 18001 and ISO 10015) through MISWEB was measured. Specifically, the satisfaction rates of the faculty members, and the administrative staff on the procedures, forms and documents of IMS. Many tools and methods such as the tables, figures, and shape in addition to the Likert scale for the surveys were used to illustrate the impact of the IMS. A group of faculty members and the administrative staff have been surveyed over five years. The number of those samples from the two surveys were (152, $159,125,120,82)$ for the years $(2015,2016,2017,2018,2019)$ respectively. The analysis of data went through several steps such as the average scores and the range was from (3.87 to 4.45) out of 5. Moreover, the standard deviation of the data was measured and ranged between (0.67 and 1.08). The results of the Cronbach Alpha tests reached (0.89). The overall satisfaction rate of the faculty members and administrative staff on the procedures, forms and documents in the IMS at the MISWEB website were (86\%). The satisfaction rate of the faculty members on the clarity of responsibilities in the procedures and clarity of procedures were $(93 \%)$. While, the satisfaction rate of administrative staff on the clarity of procedures and forms, the extent of updating these forms, the suitability of these procedures and forms is equivalent to (80\%). These results have led to improving the integrated management system. As well as enhance the work of MISWEB and pursue the satisfaction of faculty members and administrative staff to ensure high-quality services.

Keywords: Satisfaction Rate, ISO, Integrated Management System, Electronic Document Management System.

Copyright @ 2020: This is an open-access article distributed under the terms of the Creative Commons Attribution license which permits unrestricted use, distribution, and reproduction in any medium for non-commercial use (NonCommercial, or CC-BY-NC) provided the original author and sources are credited.

\section{INTRODUCTION}

Technical institutes are considered as one of the available educational solutions to qualify human cadres, capable to meet the requirements of the labor markets. These institutes are characterized by shorter periods of training and a tendency to train on the practical side greater than the theoretical side. This increasing emphasis on technology represents a vital element of current educational reform intended to develop a more highly skilled workforce. In Saudi Arabia, the 100,000 students receiving vocational education in 2014 are projected to reach 450,000 by
2020 [1]. In addition to that in the last six years, Saudi Arabia has established a large number of modern technical institutes that have broken universal boundaries and have been extended to the far-flung areas of the country. Presently there are 68 degreeawarding universities and institutes [2]. Saudi Arabia has a very high and stable demand for higher education as evidenced by the fact that $44 \%$ of the population in the 25-39 years age category have higher education degrees. The enrolment rates for higher education have been rising and the annual growth rates of graduates produced by different institutions have been in the 
range of 5-36\% [3]. In Saudi Arabia, technical education has been supported by the government as an important contributor to the national economic and sustainable development [4].

\section{The importance of quality in technical institutes}

The importance of quality in the technical institutes would come from the need of raising the efficiency of the operation to graduate the largest number of qualified trainees, for the sake of meeting the requirements of the changing labor markets. Internally, the quality could include the training curricula, the competence of the training staff, the facilities and the necessary training equipment for the training process. Quality also includes the training process itself and other associated and supportive processes. The student in higher education plays both roles as an internal and external customer. Therefore, their satisfaction and perception of service quality are the potential to bridge the emergence of external satisfaction [5]. Moreover, the technical and Vocational Training Corporation (TVTC) is increasingly recognized as the bedrock of every development, quality assurance and leads to the production of qualitative human capital for sustainable national development [6]. In their strategic plan, TVTC emphasized the importance of offering training with sufficient quality, and the plan's third strategic objective stated that TVTC shall offer its educational and training programs with sufficient quality that trainees will qualify to attain a proper job in the labor market. It should be recognized that attaining quality requires the continuous improvement of performance [4]. On the other hand, the focus on quality should not go deep since, some vocational colleges only regard the students' skills and the employment rate of students as their ultimate goal, while ignoring the humanistic quality of students. In this way, the trained talents often have professional skills, but they lack the overall quality, especially the humanistic quality. Therefore, it is urgent to strengthen the humanistic quality of students in vocational colleges [7].

\section{ISO certificates}

The International Organization for Standardization (ISO) is a worldwide federation of national standards bodies (ISO member bodies). The ISO work on develops and publish International Standards. The ISO 9001 Quality Management System is one ISO Standards that help to improve the institute overall performance and provide a sound basis for sustainable development initiatives. The benefits of ISO 9001 summarized as follows; the ability of the institute to consistently provide services that meet customer and applicable statutory and regulatory requirements; facilitating opportunities to enhance customer satisfaction; addressing risks and opportunities associated with its context and objectives; the ability of the institute to demonstrate conformity to specified quality management system requirements [8]. Moreover, The Occupational Health and Safety
Assessment Series (OHSAS) Standard specifies requirements call them OHSAS 18001 for an occupational health and safety $(\mathrm{OH} \& \mathrm{~S})$ management system, to enable an organization to control its $\mathrm{OH} \& \mathrm{~S}$ risks and improve its $\mathrm{OH} \& \mathrm{~S}$ performance. The benefits of OHSAS 18001 summarized as follows; the institute could establish an $\mathrm{OH} \& \mathrm{~S}$ management system to eliminate or minimize risks to personnel and other interested parties who could be exposed to $\mathrm{OH} \& \mathrm{~S}$ hazards associated with its activities; implement, maintain and continually improve an OH\&S management system; assure itself of its conformity with its stated $\mathrm{OH} \& \mathrm{~S}$ policy; demonstrate conformity with this OHSAS Standard [9]. The International Standard specifies requirements call them ISO 22000 for a food safety management system where an organization in the food chain needs to demonstrate its ability to control food safety hazards in order to ensure that food is safe at the time of human consumption. The benefits of ISO 22000 summarized as follows; the institute would plan, implement, operate, maintain and update a food safety management system aimed at providing products that, according to their intended use, are safe for the consumer, demonstrating compliance with applicable statutory and regulatory food safety requirements, evaluate and assess customer requirements and demonstrate conformity with those mutually agreed customer requirements that relate to food safety, in order to enhance customer satisfaction, effectively communicate food safety issues to their suppliers, customers and relevant interested parties in the food chain, ensure that the institute conforms to its stated food safety policy, demonstrate such conformity to relevant interested parties [10]. Finally, the guidelines ISO 10015 covers the development, implementation, maintenance, and improvement of strategies and systems for training that affect the quality of the products supplied by an organization. This ISO 10015 Standard applies to all types of organizations. Training providers may use this ISO 10015 Standard when addressing the training needs of their own personnel [11].

\section{The Integrated Management System (IMS)}

The IMS could consider as one of the most important factors that eases the process of integrating many ISO systems into one system to facilitate the implementation of the systems. Especially for the customers and the users of these ISO systems. The IMS view as a complete management system which applied across the entire institute in order to meet the customers' requirements to deliver services at highquality levels. The IMS at JTI has included the procedures and other documents of the quality management system (ISO 9001), the OH\&S activities and processes (ISO 22000), food safety and health activities and processes (OHSAS 18001) and the staff training guidelines that affect service quality (ISO 10015). Integration of management systems brings the most diverse benefits for organization, benefits that can 
be translated into a more efficient organization activity and, consequently, increase business performance, throughout reduce costs and add value to processes or to reduce business risks, representing a valuable opportunity to optimize documentation and audit processes analysis and inter-functional communication [12]. It can be handled by internal departmental crossfunctional team. The savings in the resources and manpower are evident. Internal departmental barriers are reduced with cross-functionality. The documentation required is also common for the management of the integrated management system. The cost savings can be done in the external audits mandays also [13]. Different management systems can be insightful when answering the challenge of achieving sustainability. The maturity of management system integration can lead to better sustainable performance [14]. The aforementioned management systems are applicable to any type and size of organizations with diverse geographical, cultural and social conditions whereby it can also be integrated with other management systems that can suit the context of the company [15].

\section{Background}

Achieving the goals of ISO quality systems throughout the IMS are important strategic objectives for each training institution. They work continuously in evaluating the strength and the weakness of the institute. Moreover, these goals reduce the rate of errors, the time required to complete tasks with clearly defined responsibilities, ultimately they help to achieve customer satisfaction and optimize the available resources. The implementation of the quality management system at vocational institutions could be on the following elements: customer focus, principal leadership, teams and teachers, quality goals, student learning which is increasing, problem solving and consultation, selection stage of students [16]. In the safety management case, Management commitment and supportive environment influence could encourage the OHSAS 18001 management system adoption. Management commitment is the most important determinant in the OHSAS 18001 management system adoption. Since top management is the main decisionmaker of the organization, management is required to analyze and evaluate the need for the company to adopt the OHSAS 18001 management system. In addition, a supportive environment should be made to the OHSAS 18001 steering committee to fully implement the OHSAS management system in the organization. This supportive environment can be in the form of positive work behaviors, and work practices of the employees, as well as organizational culture with respect to the safety and health at the workplace [17]. The organizations whose processes make less visible the consequences of work accidents might cultivate training programs that function better under these conditions. The training might function not only by disseminating safety knowledge to employees but also by imparting them relevant information and practical experience about work risks which are critical to assimilate, clarify and verify the value of safety knowledge [18]. In the food safety case, the trust that has been given to partnerships and employers' forums if they were involved in specific projects was identified. Avoiding prescriptive content, updating the terms and phrases, changing the shape, harmonizing the structure with other referential to avoid overlapping are key elements that will underpin the new version of the ISO 22000 standard [19]. In addition to that, over the past years, quality management and product safety have been perceived by many national and international organizations as an accurate and clearly defined approach for defining and fulfilling the requirements in all aspects. In this sense, safety management of the foodstuffs produced is in itself the application of certain methods of work and consumer relationships, which feature as requirements in international standards such as ISO 9001, ISO 22000 and others [20]. In the training quality case, The ISO 10015 was built to identify and develop key quality performance to create a wellplanned, cost-effective education, and training system. An organization can enhance its competitive advantage by continually improving the quality of its human resources and thus improving capability and performance. ISO 10015 helps a company link training and education to performance objectives. Such a training method provides companies with continuous feedback regarding their investment in human competencies [21].

\section{Types of implementation of the integration of ISO systems}

Integration means linking a set of parts in one unit. In a management context, it is intended to place all internal management applications in one system and link the different processes together to solve a specific problem and achieve a specific goal [22]. It is also noted that there is no specific theory that describes IMS so far; and here where the difficulty arises in standardizing this system due to its complexity [23]. There are many types of implementation of the integration of ISO systems and IMS including; the classical method: which is the most used of all organizations, and it adopted basically by all the certification bodies, due to its ease and clarity of steps of formulating, implementing and monitoring IMS. The systematic model: which is focuses on how to link the three main management systems. The synergetic model: which shows the synergy between the various requirements of ISO 9001, ISO 14001, and OHSAS 18001 such as Documentation, Policies, Objectives, Management Commitment, Continuous Improvement, Audit and Internal Communication [23].

\section{The impact of MISWEB}

MISWEB is an internal website with internal web pages that organize the integration of quality systems in IMS and provide many internal services. 
One of the benefits of this website is the accessibility of all employees to the various procedures, forms and documents on the website throughout the day hours, effortlessly, at lower costs, high credibility, and reliability. Throughout the MISWEB, JTI has been developed many procedures and forms to communicate them for the sake of increasing the use of forms, procedures and notes the problems that associate with them to do the necessary actions. This practice is applied in many organizations; many global organizations have aligned their strategy and operation via the ISO-based framework of the integrated management system (IMS) that allows the merge of quality, environment, and health and safety management systems. In such a context, having a robust Electronic Document Management System (EDMS) is essential, especially at global enterprises, where a large amount of documents generated by processes, flows through different work cultures [24]. There are many benefits to this electronic system, including the following: the IMS improvement and effectiveness have been overlooking EDMS as a key factor in establishing appropriate technological support of the IMS processes. The rightful application of EDMS can further contribute to continuous improvement by advancing the document controlling processes and facilitating organizational learning and crossorganizational collaboration [24].

\section{Customer focus and the IMS}

The principle of customer focus comes from the importance of the client themselves, whether the internal clients were employees or trainees within the Institute or external clients such as public and private companies, and even the family or society. The ISO 9001 standard clarifies the meaning of customer focus as commitment that the top management shall demonstrate their leadership and commitment with respect to customer focus by ensuring customer and applicable statutory and regulatory requirements are determined, understood and consistently met; the risks and opportunities that can affect conformity of products and services and the ability to enhance customer satisfaction are determined and addressed; the focus on enhancing customer satisfaction is maintained [8]. So the IMS helped to focus on the customer, the idea behind the concept of IMS is that an organization work to the maximum extent and manage its operations through one Integrated Management System (IMS). Thereby catering to the needs of every aspect of the business; including customer satisfaction, quality of goods/services produced, cost-saving, employee benefit, working environment and the impact of the organization's operations on the society [25]. Meeting the customers' requirements could become the most important inputs that continuous improvement is built on. Therefore, customer satisfaction could be an indicator of the difference between performance and expectations. The ISO 9001 standard clarifies the meaning of customer satisfaction as that, the organization shall monitor customers' perceptions of the degree to which their needs and expectations have been fulfilled, and determine the methods for obtaining, monitoring and reviewing this information. Examples of monitoring customer perceptions can include customer surveys, customer feedback on delivered products and services, meetings with customers, market-share analysis, compliments, warranty claims and dealer reports [8]. fundamentally this is an integrated management philosophy comprising the set of practices emphasizing continuous improvement, meeting customers' requirements, reducing re-work, long-term thinking, increased employee involvement and teamwork, process re-design, team-based problemsolving, constant measurement of results, and closer relationships with suppliers [26].

\section{Jubail Technical Institute (JTI)}

Jubail Technical Institute is one of the most important technical institutes in the Kingdom of Saudi Arabia. It is supported by the Royal Commission for Jubail and Yanbu through the colleges and institutes sector. JTI strives to fulfill its mission to meeting the needs of the industrial sector from the skilled technicians who are effectively trained in dealing with modern industrial technology. The Institute has highly qualified training staff to achieve its vision of being the standard of excellence in technical training and small and medium-sized enterprises across the Arab Gulf States. JTI obtained ISO 9001 certificate in 2015, followed by several certificates such as ISO 22000 , OHSAS 18001 and ISO 10015 respectively, thus achieving ISO and OHSAS certificates in several fields, the institute had been received the institutional accreditation last year from the Education and Training Evaluation Commission, the governmental body responsible for accrediting institutes in the Kingdom. The Institute has a range of different skills/specialties within five departments such as the basic skills department, electrical and electronic skills department, mechanical skills department, chemical skills department and computer and information technology department. The trainees are admitted to the institute at a rate of (1200) trainees in the academic year.

\section{RESEARCH OBJECTIVES}

This case study aims to identify the impact of integrating the ISO/ OHSAS systems (ISO 9001, ISO 22000, OHSAS 18001 and ISO 10015) into one integrated management system through one website (MISWEB) at JTI. Also, it aims to know the success level of this experimental process. Fulfilling these aims by measuring the satisfaction rates of the faculty members and the administrative staff on the procedures, forms, and documents of ISO, OHSAS systems in order to increase operational efficiency, reduce costs and develop the website. 


\section{RESEARCH METHODOLOGY}

The day-to-day interaction of faculty members and the administrative staff with the IMS which containing ISO 9001, ISO 22000, OHSAS 18001 and ISO 10015 through the MISWEB website enabled them to evaluate the procedures, forms, and documents of these systems. The requirements of the IMS and according to the organizational structure of JTI which distributes the authorities and responsibilities of procedures, forms and documents to the departments and units as shown in table 1 . Since the total numbers of these procedures, forms, and other documents were (664 documents).

Table-1: Number of Documents vs. Departments and Units

\begin{tabular}{|llc|}
\hline No. & Department & Number of Document \\
\hline $\mathbf{1}$ & ADMN & 141 \\
\hline $\mathbf{2}$ & IDC & 39 \\
\hline $\mathbf{3}$ & IR & 50 \\
\hline $\mathbf{4}$ & MEC & 48 \\
\hline $\mathbf{5}$ & MIS & 14 \\
\hline $\mathbf{6}$ & SPU & 13 \\
\hline $\mathbf{7}$ & STA & 54 \\
\hline $\mathbf{8}$ & CITS & 2 \\
\hline $\mathbf{9}$ & DIR & 27 \\
\hline $\mathbf{1 0}$ & ETA & 101 \\
\hline $\mathbf{1 1}$ & DQA & 157 \\
\hline $\mathbf{1 2}$ & SSU & 18 \\
\hline Total & & 664 \\
\hline & & \\
\hline
\end{tabular}

Accordingly, all these IMS requirements of procedures, forms and documents have been merged into the MISWEB website to facilitate the access of the faculty members and the administrative staff to benefiting from these documents through one platform as shown in Figure 1. Which shows the Integrated Management System in MISWEB.

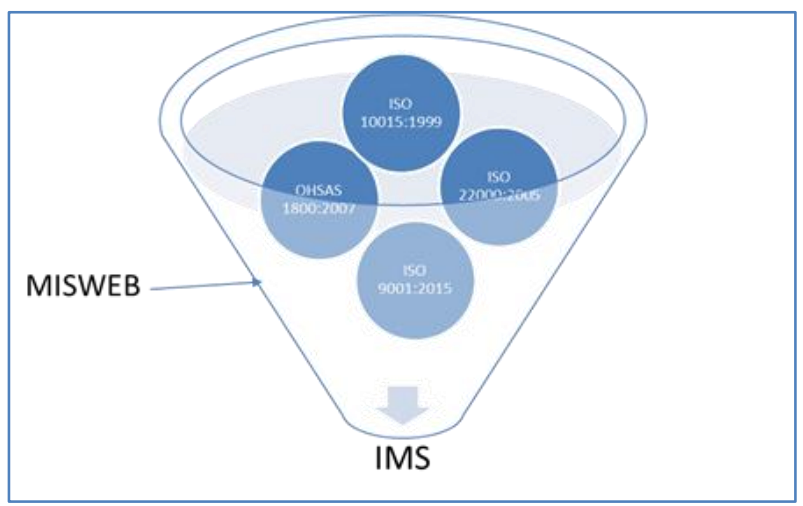

Fig-1: The Integrated Management System in MISWEB

This integration resulted in the IMS, which sometimes unites a single procedure that serves many requirements of ISO systems such as internal audit procedures and others. Table 2, summarizes the type of documents against the number of documents in MISWEB.

Table-2: Type of Documents vs. Number of Documents in MISWEB

\begin{tabular}{|c|c|c|}
\hline No. & Type of Document & Number of Document \\
\hline 1 & Procedures & 186 \\
\hline 2 & Forms & 229 \\
\hline 3 & Documents & 17 \\
\hline 4 & References & 22 \\
\hline 5 & Attachments & 208 \\
\hline 6 & Manual & 2 \\
\hline \multicolumn{2}{|r|}{ Total } & 664 \\
\hline
\end{tabular}




\section{Surveys and feedback}

After designing the IMS, the feedback was taken by the direct users in the institute for the last five years, namely the faculty members and the administrative staff. These surveys were carried out through a variety of samples from these two categories over the past years. In the administrative staff survey, the focus was on three aspects: clarity of the procedures, match between the written procedures and the real work, suitability of the forms and records. The survey of the faculty members was focused on two aspects: efficiency of the procedures and separation of the responsibilities. Knowing that these surveys were extensive ones with many topics, but to limit this study to the research purposes we have satisfied with the selected questions. The Likert scale has been used when implementing these surveys, and the categories contain strongly agree, agree, disagree, strongly disagree, neutral or not Applicable. The numbers (5), (4), (3), (2) and (1) were assigned to the abovementioned categories respectively. Satisfaction rates for each aspect of the survey were calculated over the years and the averages, standard deviation were taken for each year to track the development and deficiencies in the IMS. The quality of the survey data was measured by the Alpha Cronbach Test.

\section{Targeted samples in the study}

The main users of IMS are faculty members and the administrative staff. A large group of them have been sampled over five years. The number of those surveyed from the administrative staff was $(89,89,69$, $50,42)$ for the years $(2015,2016,2017,2018,2019)$ respectively. While, the number of respondents of the faculty members team was $(63,70,56,70,44)$ for the years $(2015,2016,2017,2018,2019)$ respectively. The total number of employees at JTI ranges between (170 to 190 faculty and staff members). These employees come from (15) administrative, training departments and small units.

\section{RESULTS \\ Faculty members survey results}

From the survey results of the faculty members, we noted that the satisfaction with the procedures and forms in the IMS were ranged between ( $88 \%$ and $96 \%$ ) during the past five years. When they asked about the efficiency of the procedures and separation of the responsibilities, as shown in table 3.

When they asked about the efficiency of the procedures and their satisfaction with them, it was noted that their level of satisfaction generally increased. Their average satisfaction over the past five years was (91\%). While, when they asked about the separation of the responsibilities in these procedures, forms, the result was almost stable at a higher level. Their average satisfaction over the past five years was (94\%), as shown in table 3 .

Table-3: Satisfaction Rate of the Faculty Members

\begin{tabular}{|ccc|}
\hline \multirow{2}{*}{ Year } & \multicolumn{2}{c|}{ Questions } \\
\cline { 2 - 3 } & Procedures Are Efficient & Responsibilities Are Defined \\
\hline $\mathbf{2 0 1 5}$ & $90 \%$ & $93 \%$ \\
\hline $\mathbf{2 0 1 6}$ & $88 \%$ & $94 \%$ \\
\hline $\mathbf{2 0 1 7}$ & $91 \%$ & $94 \%$ \\
\hline $\mathbf{2 0 1 8}$ & $94 \%$ & $96 \%$ \\
\hline $\mathbf{2 0 1 9}$ & $93 \%$ & $93 \%$ \\
\hline Average & $\mathbf{9 1 \%}$ & $\mathbf{9 4 \%}$ \\
\hline
\end{tabular}

Generally, the average satisfaction of the faculty members with the procedures, forms and documents in the IMS on the MISWEB website, has been steadily increasing as shown in Figure 2. The highest satisfaction rate was in 2018.

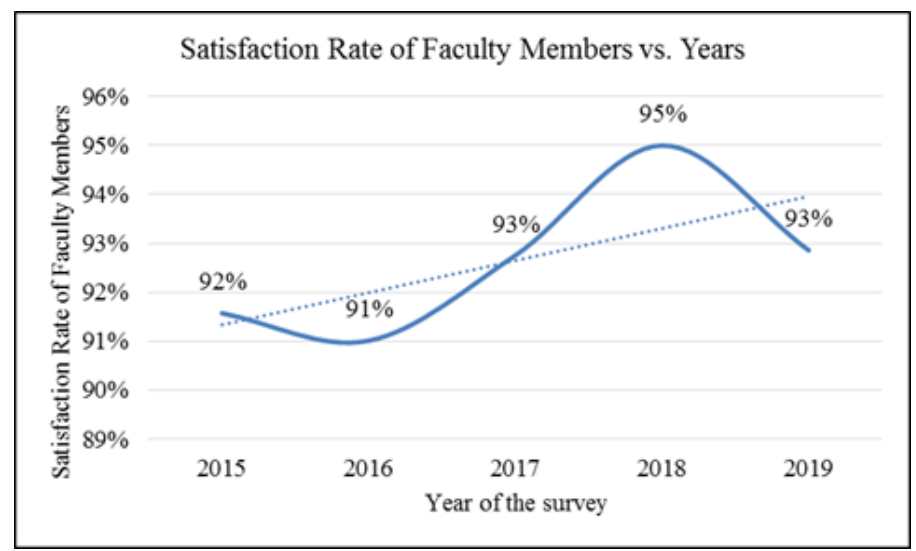

Fig-2: Satisfaction Rate of Faculty Members vs. Years 
To determine the quality of the obtained survey data, the average scores were calculated for each option of the survey. The average ranged from (4.27 to 4.45). Moreover, the standard deviation of the data was measured to show the extent of statistical scattering and to find out how the results are close or far from the mean. The standard deviation was ranged between $(0.67$ and 0.99). At the end of this section, the Cronbach
Alpha test, which is a measure and indicator of the reliability of the survey. It's also, reflects the reliability and consistency of the survey results. The results in the last three years have been better than the two years before. In the last three years, it ranged between $(0.72$ and 0.84 ), which gives more reliability in these results, as in table 4 .

Table-4: Statistical Indicators of the Survey's Faculty Members

\begin{tabular}{|cccc|}
\hline \multirow{2}{*}{ Year } & \multicolumn{3}{c|}{ Statistical Indicators } \\
\cline { 2 - 4 } & Average & Standard deviation & Cronbach's alpha \\
\hline $\mathbf{2 0 1 5}$ & 4.41 & 0.81 & 0.62 \\
\hline $\mathbf{2 0 1 6}$ & 4.35 & 0.81 & 0.57 \\
\hline $\mathbf{2 0 1 7}$ & 4.39 & 0.67 & 0.84 \\
\hline $\mathbf{2 0 1 8}$ & 4.27 & 0.99 & 0.72 \\
\hline $\mathbf{2 0 1 9}$ & 4.45 & 0.67 & 0.81 \\
\hline Average & $\mathbf{4 . 3 7}$ & $\mathbf{0 . 7 9}$ & $\mathbf{0 . 7 1}$ \\
\hline
\end{tabular}

\section{Administrative staff survey results}

From the results of the survey of the administrative staff, we noted that the satisfaction with the procedures and forms in the IMS were ranged between (67\% and 91\%) during the past five years. When they asked about the clarity of the procedures, match between the written procedures and the real work, suitability of the forms and records, as shown in table 5 .
When they asked about the clarity of the procedures, it was noted that their average level of satisfaction over the past five years was $(79 \%)$. While, when they asked about the match between the written procedures and the real work, the result over the past five years was $(78 \%)$. While, when they asked about the suitability of the forms and records, the result over the past five years was $(82 \%)$, as shown in table 5 .

Table-5: Satisfaction Rate of the Administrative Staff

\begin{tabular}{|cccc|}
\hline Year & $\begin{array}{c}\text { Procedures } \\
\text { are clear }\end{array}$ & $\begin{array}{c}\text { Procedures match the real } \\
\text { work procedure }\end{array}$ & $\begin{array}{c}\text { Forms and records } \\
\text { are suitable }\end{array}$ \\
\hline $\mathbf{2 0 1 5}$ & $81 \%$ & $67 \%$ & $76 \%$ \\
\hline $\mathbf{2 0 1 6}$ & $77 \%$ & $71 \%$ & $81 \%$ \\
\hline $\mathbf{2 0 1 7}$ & $91 \%$ & $80 \%$ & $84 \%$ \\
\hline $\mathbf{2 0 1 8}$ & $71 \%$ & $86 \%$ & $86 \%$ \\
\hline $\mathbf{2 0 1 9}$ & $77 \%$ & $84 \%$ & $84 \%$ \\
\hline Average & $\mathbf{7 9 \%}$ & $\mathbf{7 8 \%}$ & $\mathbf{8 2 \%}$ \\
\hline
\end{tabular}

To determine the quality of the obtained survey data, the average scores were calculated for each option of the survey. The average ranged from (3.87 to 4.19). Moreover, the standard deviation of the data was measured to show the extent of statistical scattering and to find out how the results are close or far from the mean. The standard deviation was ranged between $(0.75$ and 1.08). At the end of this section, the Cronbach Alpha was tested as a measure and indicator of the reliability of the survey. It's also, reflects the reliability and consistency of the survey results. The results in the last five years have been ranged between $(0.80$ and $0.89)$, which gives more reliability in these results, as in table 6 .

Table-6: Statistical Indicators of the survey's Administrative Staff

\begin{tabular}{|cccc|}
\hline \multirow{2}{*}{ Year } & \multicolumn{3}{c|}{ Statistical Indicators } \\
\cline { 2 - 4 } & Average & Standard deviation & Cronbach's alpha \\
\hline $\mathbf{2 0 1 5}$ & 3.87 & 1.03 & 0.81 \\
\hline $\mathbf{2 0 1 6}$ & 3.94 & 0.90 & 0.85 \\
\hline $\mathbf{2 0 1 7}$ & 4.13 & 1.08 & 0.89 \\
\hline $\mathbf{2 0 1 8}$ & 4.19 & 0.75 & 0.87 \\
\hline $\mathbf{2 0 1 9}$ & 3.99 & 0.89 & 0.80 \\
\hline Average & $\mathbf{4 . 0 2}$ & $\mathbf{0 . 9 3}$ & $\mathbf{0 . 8 4}$ \\
\hline
\end{tabular}


Generally, the average satisfaction of the administrative staff with the procedures, forms and documents in the IMS on the MISWEB website, has been steadily increasing as shown in Figure 3. The highest satisfaction rate was in 2017.

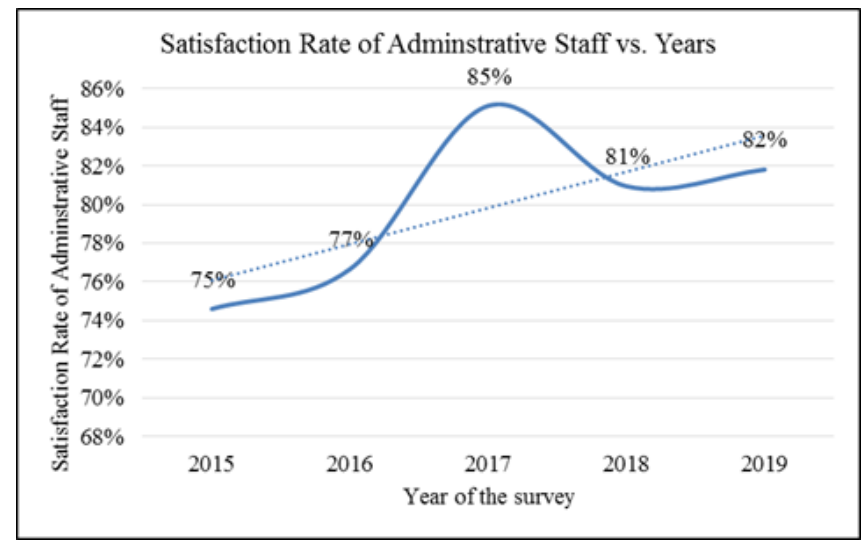

Fig-3: Satisfaction Rate of Administrative Staff vs. Years

As shown in Figure 4 below, it is clear that the average rate of satisfaction of faculty members and administrative staff have been increased continually, where the rate of increase during the past five years is equivalent to $(5 \%)$.

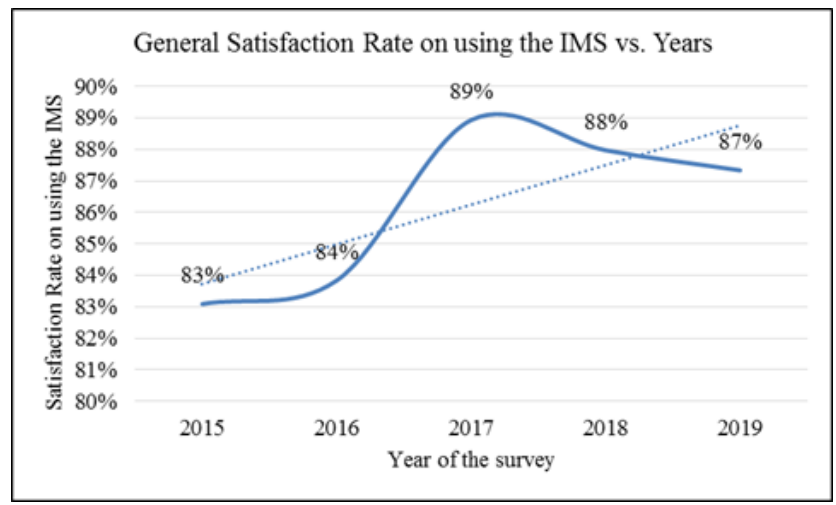

Fig-4: General Satisfaction Rate of all Staff vs. Years

\section{CONCLUSION AND RECOMMENDATION}

The overall satisfaction of the faculty members and administrative staff on the procedures, forms, and documents in the IMS at the MISWEB website were $(86 \%)$. This could reflect the development of JTI IMS. The satisfaction rate of the faculty members on the clarity of responsibilities in the procedures and clarity of procedures were $(93 \%)$. While the satisfaction rate of administrative staff on the clarity of procedures and forms and the extent of updating these forms and the suitability of these procedures and forms is equivalent to $(80 \%)$. However, these results illustrate the continuous development of the IMS, which included the ISO 9001, ISO 22000, OHSAS 18001 and ISO 10015 and its suitability for the users. Based on the eased access to procedures, forms, and documents on the MISWEB website. Moreover, the integration of some procedures, forms, and integration have been supported the employees in all departments and units in JTI. This was assisted by the use of the MISWEB website, which served as a platform and store for all procedures, forms, and documents. Employees could easily access the documents with high security as it is an internal website at JTI. However, the possibility of browsing the approved procedures and documents in pdf format and download the forms in Microsoft formats and work on them quite easily according to the procedures. Thus, many of the goals and objectives of the implementation of ISO systems have been achieved by integrating them into the Integrated Management System through the MISWEB platform. This was done and audit through external auditors, their frequent periodic audit visits and the continuation and upgrading of modern versions of ISO certifications. For example, the ISO 9001, ISO 22000 .

All of this has been reflected in raising the quality of services at JTI and its excellence to achieve its vision to be the standard of excellence in the Arabian Gulf States in the field of qualifying skilled human cadres of technicians and providing services to entrepreneurs in small and medium enterprises. Through the distinguished human cadre who working in the Institute, which by achieving their satisfaction with the IMS, the efficiency of operation would increase and the costs of providing services would reduce too. One 
of the recommendations of this case study is that the need for quality and safety committees and other committees for the sake of implementing the standards and fulfills requirements of quality and safety systems should be strengthened. The case study also recommends that the need to include any new system within the same IMS through MISWEB website in order to facilitate the use and application of the systems. Moreover, to enhance the work of MISWEB and increase the efficiency of the IMS, the case study recommends adding extra performance indicators to increase the effectiveness of the use of the MISWEB website. Meanwhile, efforts to enhance the satisfaction of faculty members and administrative staff should be pursued to ensure high-quality services.

As part of the continuous improvement and enhancement of the quality of the provided services at the Institute, the MISWEB website has been established as a platform for IMS. Over the past years, MISWEB has been continuously monitored and maintained to avoid system problems. Many databases have been developed resulting from the use of the quality systems where it can follow any process and develop it. A range of quality and safety systems tools such as internal audits were used by specialized committee members to ensure the effective implementation of the IMS. Various periodic surveys were conducted in several fields, and reports and recommendations were issued. All these initiatives and others have been implemented to achieve the implementation of the Institute's mission and within the framework of a comprehensive strategic plan. Finally, additional studies could be conducted to determine the differences between the observed satisfaction rates of administrative staff and faculty members during this study.

\section{ACKNOWLEDGEMENTS}

In conclusion, we thank Allah for health and wish success to this case study. We also extend our sincere thanks to the Royal Commission for Jubail and Yanbu and Jubail Technical Institute for their continued support and encouragement of scientific research projects.

\section{REFERENCES}

1. Lawrence, B. A. M. (2016). IPad Acceptance by English Learners in Saudi Arabia. English Language Teaching, 9(12), 34-46.

2. Meo, S. A. (2015). Saudi Arabia: A future regional hub for advanced education, research, science and technology. JPMA. The Journal of the Pakistan Medical Association, 65(10), 1112-1115.

3. Ghulam, Y., \& Mousa, W. I. (2019). Estimation of productivity growth in the Saudi higher education sector. Technological Forecasting \& Social Change, 149.

4. Alzamil, Z. A. (2014). Quality improvement of technical education in Saudi Arabia: self-evaluation perspective. Quality Assurance in Education: An International Perspective, 22(2), 125.

5. Rahayu, S. (2018). Customer Satisfaction and Service Quality to Develop Trust and Positive Word of Mouth in Vocational Education. KnE Social Sciences \& Humanities, 2018, 356-371.

6. Ayonmike, C. S., Okwelle, P. C., \& Okeke, B. C. (2015). Towards Quality Technical Vocational Education and Training (TVET) Programmes in Nigeria: Challenges and Improvement Strategies. Journal of Education and Learning, 4(1), 25-34.

7. Juan, Lei., \& Mengdan Xu. (2018). Ways to Improve Students' Humanistic Quality in Vocational Colleges. KnE Social Sciences \& Humanities, 2018, 1723-1728.

8. International standard. (2015). Quality management systems - Requirements, (ISO 9001:2015)

9. International standard. (2007). Occupational health and safety management systems -Requirements, (OHSAS 18001:2007)

10. International Standard. (2005). Food safety management systems - Requirements for any organization in the food chain, (ISO 22000:2005)

11. International Standard. (1999). Quality management - Guidelines for training, (ISO 10015:1999)

12. Maier, D., Vadastreanu, A. M., Keppler, T., Eidenmuller, T., \& Maier, A. (2015). Innovation as a Part of an Existing Integrated Management System. Procedia Economics and Finance, 26, 1060-1067.

13. Jewalikar, A. D., \& Shelke, A. (2017). Lean Integrated Management Systems in MSME Reasons, Advantages and Barriers on Implementation. Materials Today: Proceedings, 4(2), 1037-1044.

14. [14] Poltronieri, C. F., Ganga, G. M. D., \& Gerolamo, M. C. (2019). Maturity in management system integration and its relationship with sustainable performance. Journal of Cleaner Production, 207, 236-247.

15. Muhamad Khair, N. K., Lee, K. E., Mokhtar, M., \& Goh, C. T. (2018). Integrating responsible care into quality, environmental, health and safety management system: A strategy for Malaysian chemical industries. Journal of Chemical Health \& Safety, 25(5), 10-18.

16. Istriani, R. N., \& Rahardja, S. (2019). Implementation Quality Management System of ISO 9001: 2015 at Vocational High School Yappi Wonosari Gunungkidul Regency. KnE Social Sciences \& Humanities, 478-485.

17. Ling, T. C., Hashim, F., \& Liang, C. W. (2015). Occupational Health and Safety Advisory Services (OHSAS) 18001 management system adoption: Assessing the determinants. Jurnal Pengurusan (UKM Journal of Management), 43.

18. Lafuente, E., \& Abad, J. (2018). Analysis of the relationship between the adoption of the OHSAS 
18001 and business performance in different organizational contexts. Safety science, 103, 12-22.

19. Măzărel, A., Canja, C. M., Lupu, M. I., \& Pădureanu, V. (2017). The Impact of the Iso 22000: 2005 Standard on Food Safety in the Romanian Hospitality Industry. International Multidisciplinary Scientific Conference on Social Sciences \& Arts SGEM, 823-830.

20. Stoyanova, A. (2019). Impact of External and Internal Circumstances on Food Safety Management. Trakia Journal of Sciences, 17(Supplement 1), 386-394.

21. Chang, W.-L., \& Chen, S.-T. (2013). The performance of Taiwan's training quality excellence system. Total Quality Management \& Business Excellence, 24(5/6), 561-576.

22. Knouch, M., \& Charefeddine, M. (2018). An Overview of the Methods for the Integration of Management Systems with Examples for International Companies.
23. Knouch, M., \& Charefeddine, M. (2018). An Overview of the Methods for the Integration of Management Systems with Examples for International Companies.

24. Pho, H. T., \& Tambo, T. (2014). Integrated management systems and workflow-based electronic document management: An empirical study. Journal of Industrial Engineering and Management (JIEM), 7(1), 194-217.

25. Samy, G. M., Samy, C. P., \& Ammasaiappan, M. (2015). Integrated Management Systems for Better Environmental Performance and Sustainable Development - a Review. Environmental Engineering \& Management Journal (EEMJ), 14(5), 985-1000.

26. Peljhan, D., \& Marc, M. (2018). Total quality management and performance management systems: team players or lonely riders? Total Quality Management \& Business Excellence, 29(7/8), 920-940. 